Check for updates

London

Cite this as: $B M J$ 2021;372:n505 http://dx.doi.org/10.1136/bmj.n505 Published: 19 February 2021

\title{
Covid-19: Ethnicity vaccination gap narrows in England, but concerns remain
}

Shaun Griffin

The gap between the number of black people and white people vaccinated against covid-19 in England has slightly narrowed in the past few weeks, although it is still a concern and requires attention, say experts.

As of 13 January, data from the OpenSAFELY platform showed that twice as many white people aged over $80(43 \%)$ had been vaccinated as black people $(21 \%){ }^{1}$ By 11 February, when $91 \%$ of this age group had been vaccinated, $91 \%$ of white people had been vaccinated, compared with only $58 \%$ of black people and $72 \%$ of people from South Asian backgrounds. ${ }^{2}$

The latest dataset also looked at vaccine coverage among 70-79 year olds and showed that $85 \%$ of this age group (1.76 million) had been vaccinated by 11 February. A similar trend was seen with ethnicity, as $66 \%$ of white people in this cohort had been vaccinated, compared with $46 \%$ of black people and $62 \%$ of people of South Asian ethnicity.

Further analysis showed that vaccine coverage was lowest among people who described their ethnicity as African (49\% of over 80 and $41 \%$ aged $70-79$ ), followed by those of Bangladeshi and British Bangladeshi ethnicity (59\% over 80 and 54\% aged 70-79) and those of Caribbean ethnicity (61\% and 49\%).

\section{Building trust}

OpenSAFELY is an analytics platform for electronic NHS records, created to deliver urgent results during the global covid-19 emergency. For the studies researchers from the University of Oxford and the London School of Hygiene and Tropical Medicine examined GP records, although the analysis has not yet been peer reviewed.

The study authors noted that the variations observed should not be misinterpreted as a criticism of the NHS's vaccination campaign, adding that "further research is needed to understand and address the observed lower coverage among people from more deprived areas, and the striking disparity between ethnic groups.”

Low vaccination rates among people with severe mental illness and learning disabilities are also of concern, said the authors, who suggested that these rates "may reflect challenges around access, including for those currently living in institutional settings.”

They noted that the dataset may not be fully representative, as only $17 \%$ of general practices in London used the software, records of ethnicity were missing for $28 \%$ of people over 80 , and difficulties arose in conducting large scale studies of care home residents.
Stephen Evans, one of the project's lead researchers, told The BMJ, "The rate of rollout of the vaccination is very rapid indeed, so it is important not to draw too strong conclusions about apparent differences, since the picture is changing on a daily basis. The pattern in the first few weeks was quite different to the later data."

Gurch Randhawa, director of the Institute for Health Research at the University of Bedfordshire and coauthor of a recent $B M J$ opinion piece, ${ }^{3}$ said, "Building trust and confidence between public and government is not something that can become the norm overnight. It requires meaningful and sustained engagement and partnership working at all levels-nationally via faith leaders, role models, celebrities, etc, and at local level with trusted community organisations."

The latest update of data coincided with the launch of a television campaign encouraging vaccination among minority ethnic communities. A five minute video coordinated by Adil Ray, creator of the BBC comedy Citizen Khan, features appearances from celebrities and politicians and dispels several circulating myths. It appeared on ITV, Channel 4, and other UK commercial channels on 18 February.

1 O'Dowd A. Covid-19: Black people over 80 in England are half as likely as white people to have been vaccinated. BMJ2021;372:n357. doi: 10.1136/bmj.n357 pmid: 33547172

2 OpenSAFELY. NHS covid-19 vaccine coverage: weekly report. 16 Feb 2021 https://opensafely.org/research/2021/covid-vaccine-coverage/.

3 Randhawa G, Griffin S. Covid-19 must be a tipping point for tackling inequalities. 12 Feb 2021. https://blogs.bmj.com/bmj/2021/02/12/covid-19must-be-a-tipping-point-for-tackling-inequalities/.

This article is made freely available for use in accordance with BMJ's website terms and conditions for the duration of the covid-19 pandemic or until otherwise determined by BMJ. You may use, download and print the article for any lawful, non-commercial purpose (including text and data mining) provided that all copyright notices and trade marks are retained. 